\title{
Benign hepatic tumours and tumour like conditions
} in men

\author{
PJ KARHUNEN
}

From the Department of Forensic Medicine, University of Helsinki, Finland

SUMMARY In a consecutive medicolegal necropsy series benign hepatic tumours and tumour like conditions occurred in 52\% of the 95 men aged 35-69 years. The incidence increased with age, mainly due to small bile duct tumours $(n=26$; mean age 56.7 years; $p<0.01$; mean size $1.3 \mathrm{~mm})$. The next most common tumours were cavernous hemangiomas $(n=19$; mean age 53.9 years; mean size $5.2 \mathrm{~mm})$ that were not related to age. Focal nodular hyperplasia $(\mathrm{n}=3$; mean size $8.0 \mathrm{~mm})$ tended to occur in a younger age group (mean age 40.3 years; $p<0.001$ ). Multiple bile duct tumours were present in $46 \%$ and hemangiomas in $50 \%$ of the men studied. Liver cell adenoma, nodular regenerative hyperplasia, and peliosis hepatis were incidental findings (one case of each). Nodular regenerative hyperplasia was associated with the consumption of alcohol and a total dose of $21.5 \mathrm{~g}$ of testosterone.

These results indicate that benign hepatic tumours and tumour like conditions are not rare in men but may remain undetected because of their small size.

Benign liver tumours and tumour like conditions may arise from hepatic parenchymal cells, bile duct epithelium, blood vessels, or other mesodermal structures. $^{12}$ Most of them are considered to be rarities. $^{1-7}$ The increasing number of reports on hepatic tumours and tumour like conditions may reflect a real increase in incidence-for example, liver cell adenoma ${ }^{8}$ or peliosis hepatitis; ${ }^{9}$ or the increase may be due to improvements in diagnostic methods and surgical techniques. ${ }^{10-12}$ Potential malignant transformation has even been ascribed to some of these lesions, ${ }^{13-18}$ and some, like liver cell adenoma and peliosis, may cause life threatening haemorrhage. ${ }^{39}$

Liver cell adenoma and, to a lesser degree, focal nodular hyperplasia and cavernous hemangioma occur more often in women; bile duct adenoma is more commonly found in man. ${ }^{3}$

This study reports the occurrence, age, and sex predilection of benign hepatic tumours and tumour like conditions in a prospective necropsy series of men, which was carried out to assess the validity of reported sex differences.

\section{Material and methods}

The series comprised 95 consecutive medicolegal nec-

Accepted for publication 2 October 1985 ropsies on 35-69 year old men in the Helsinki city district in 1982. Medicolegal necropsies were undertaken because of the unexpected death of a previously healthy person, suspected suicide, poisoning, or violent death of some other type. The most common $(49.5 \%)$ causes of death were cardiovascular diseases. In total $66.3 \%$ of the deaths were caused by disease. The low incidence of death due to neoplasms $(1 \%)$ and the high proportion of intoxications due to alcohol or a combination of alcohol and drugs $(15.8 \%)$, as well as the high proportion of other violent deaths $(17.9 \%)$, characterised the medicolegal nature of the series.

\section{I.IVER SPECIMENS}

Each liver was sliced into $1-2 \mathrm{~cm}$ sections after a careful search for capsular lesions or tumours. The cut surfaces were inspected under optimal illumination, and blocks $(n=505)$ were taken from suspect areas for histology. In addition, routine blocks were taken: one from the surface of the right liver lobe at the usual site of liver biopsy, one from the inferior edge of the right lobe at the usual site of surgical biopsy, and one from the surface of the left lobe. These blocks $(n=285)$ were examined without knowledge of the results of the study on the suspected lesions. Sections were cut and stained with hematoxylin and eosin and haematoxylin and van Gieson. The maximum width 
of the tumours was measured by an ocular micrometer.

\section{CLASSIFICATION OF BENIGN HEPATIC TUMOURS}

The tumours were classified using the nomenclature and diagnostic criteria of the International Association for the Study of the Liver. ${ }^{18}$ Biliary microhamartomas and bile duct adenomas were grouped together as bile duct tumours because of their simultaneous occurrence $(15 \%)$ in the series and because of the many similarities in their morphology. ${ }^{19}$ By definition, bile duct adenomas are composed of proliferated small bile ducts lined with apparently normal epithelium set in a fibrous stroma, whereas biliary microhamartomas (von Meyenburg's complexes) have been described as collections of proliferated bile ducts and ductules set in a fibrous, often hyalinised stroma. ${ }^{18}$ In hamartoma the ducts may have undergone cystic dilatation. ${ }^{20}$

Nodular regenerative hyperplasia was defined as an entity of a diffuse, nodule forming, regenerative process without fibrosis. ${ }^{1721}$

Statistical analysis was done using the two tailed Student's $t$ test for separate variances.

\section{Results}

\section{TUMOUR TYPES}

Tumours or tumour like conditions were found in 49 patients - that is, $52 \%$ of the 95 necropsies (Table 1). The only malignant tumour was a previously undiagnosed adenocarcinoma of the colon with multiple hepatic metastases and fatal peritonitis in a 69 year old man.

All other tumours were incidental findings. The most common tumours were benign bile duct tumours (microhamartomas and adenomas) occurring in $27 \%$ (26 cases) (Fig. 1). The next most common were cavernous hemangioma in $20 \%$ (19 cases); focal nodular hyperplasia (Fig. 2a) in 3\% (three cases). One case each (1\%) of liver cell adenoma (Fig. 2b), nodular regenerative hyperplasia (Fig. 3), and peliosis hepatis (Fig. 4) were found.

Most tumours $(81 \%)$ could be seen with the naked eye. The only tumours found in the routine blocks were microscopic bile duct tumours.

\section{LOCATION AND NUMBER OF TUMOURS}

Benign bile duct tumours, peliosis hepatis, and nodular regenerative hyperplasia chiefly affected the right liver lobe, whereas two of the three solitary lesions of focal nodular hyperplasia, as well as the liver cell adenoma, were found in the left lobe. More than one bile duct tumour was found in 12 (46\%), and five patients $(19 \%)$ had four or more tumours. Multiple hemangiomas were present in $50 \%$ of the cases, and four $(21 \%)$ had four or more tumours.

\section{SIZE OF TUMOURS}

In general, most of the tumours were small $(0.3 \mathrm{~mm}$ to $30 \mathrm{~mm}$ ) (Table 1). The smallest were bile duct tumours with a mean size of only $1.3 \mathrm{~mm}$. The mean size of cavernous hemangiomas was $5.2 \mathrm{~mm}$. The lesions of focal nodular hyperplasia had a mean size of $8.0 \mathrm{~mm}$; that of the liver cell adenoma was $5.8 \mathrm{~mm}$. Nodular regenerative hyperplasia was characterised by the presence of numerous diffusely distributed purplishblue nodules ( $1-5 \mathrm{~mm})$.

Macroscopically, the liver with peliosis hepatis had four small capsular hemangioma like dark areas. On the cut surface several dozen small dark spots were seen mainly within a $30 \mathrm{~mm}$ zone beneath the capsule. In the middle of the right lobe some large hematomas up to $20 \mathrm{~mm}$ were found.

\section{AGE FACTOR}

The overall incidence of hepatic tumours increased with age (Table 2). The mean age of men with bile duct tumours was 56.7 years, which differed significantly $(p<0.01)$ from the mean age of those with tumour free livers $(51 \cdot 1$ years). The mean age of $40 \cdot 3$ years of

Table 1 Hepatic tumours and tumour like conditions in 95 consecutive necropsies on 35-69 years old men

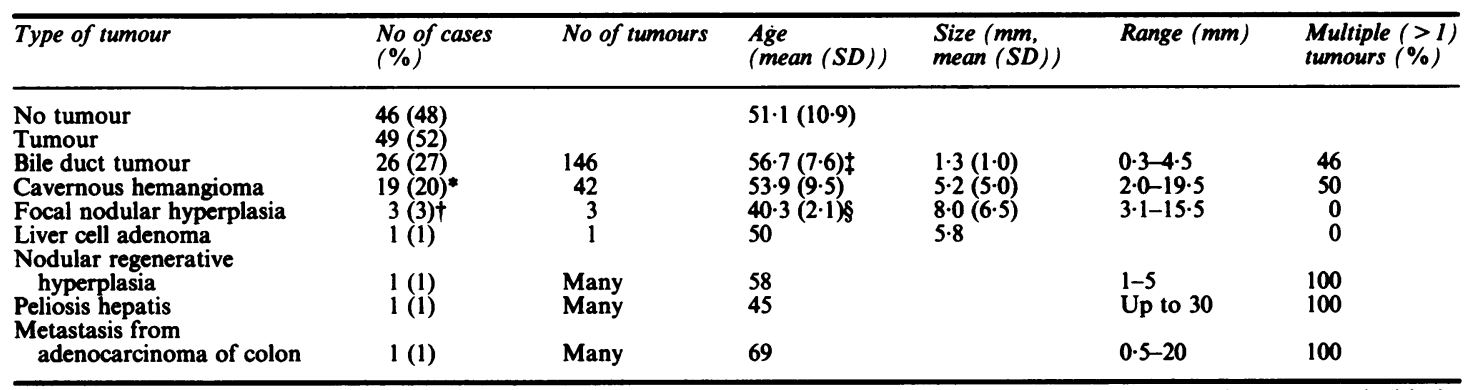

*Two patients also had bile duct tumours; †In one patient cavernous hemangioma coexisted; $\ddagger$ p $<0.01 ; \S p<0.001$ when compared with the mean age of those without tumours. 

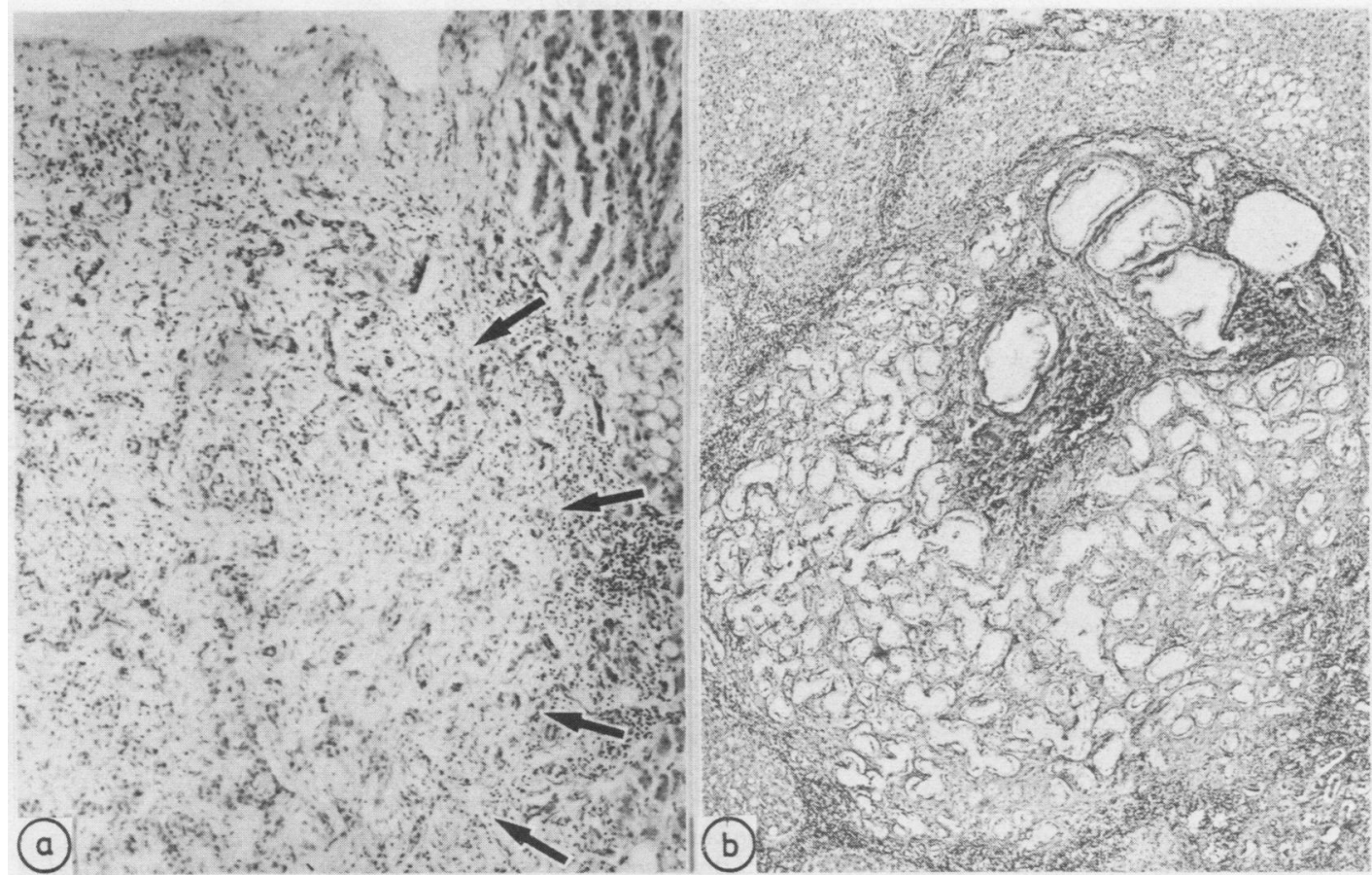

Fig. 1 Bile duct adenoma (a) located under capsule. (arrows). Bile duct microhamartoma (b) comprising a network of bile ducts connecting several portal tracts (van Gieson.) $\times 75(a), \times 30(b)$.

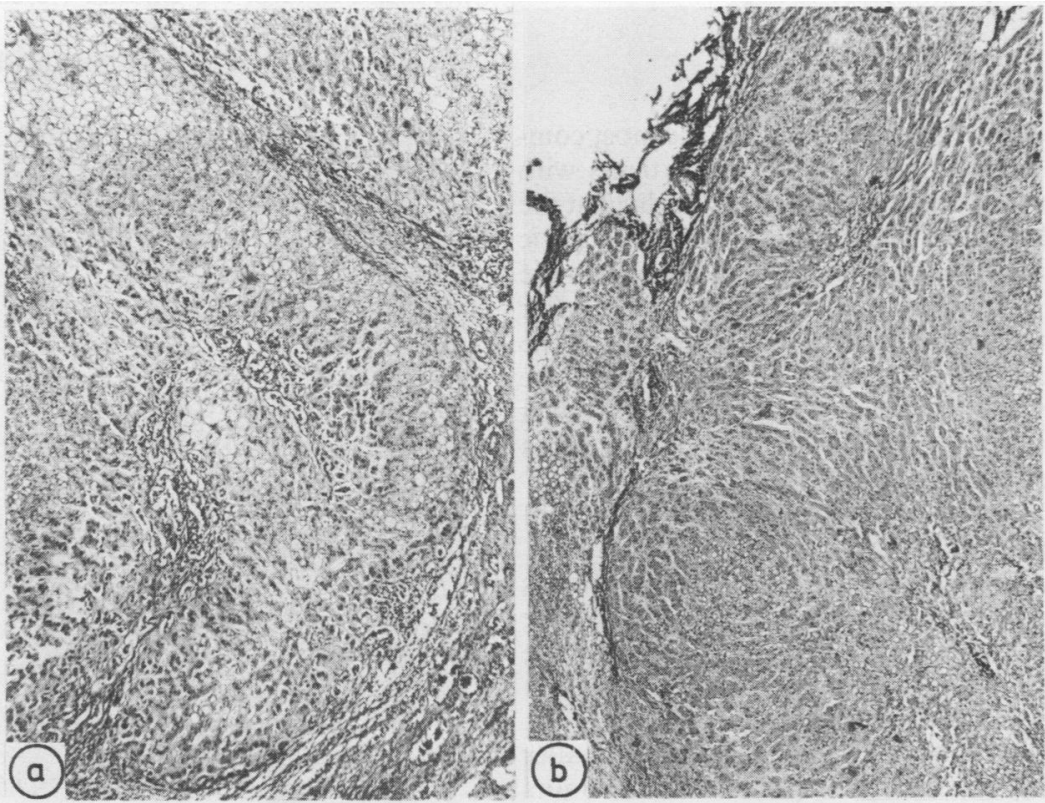

Fig. 2 Focal nodular hyperplasia (a) subdivided into nodules by fibrous septa with intense bile duct proliferation. Liver cell adenoma (b) with nodules separated by insignificant fibrotic septa. (van Gieson.) $\times 40(a), \times 30(b)$. 

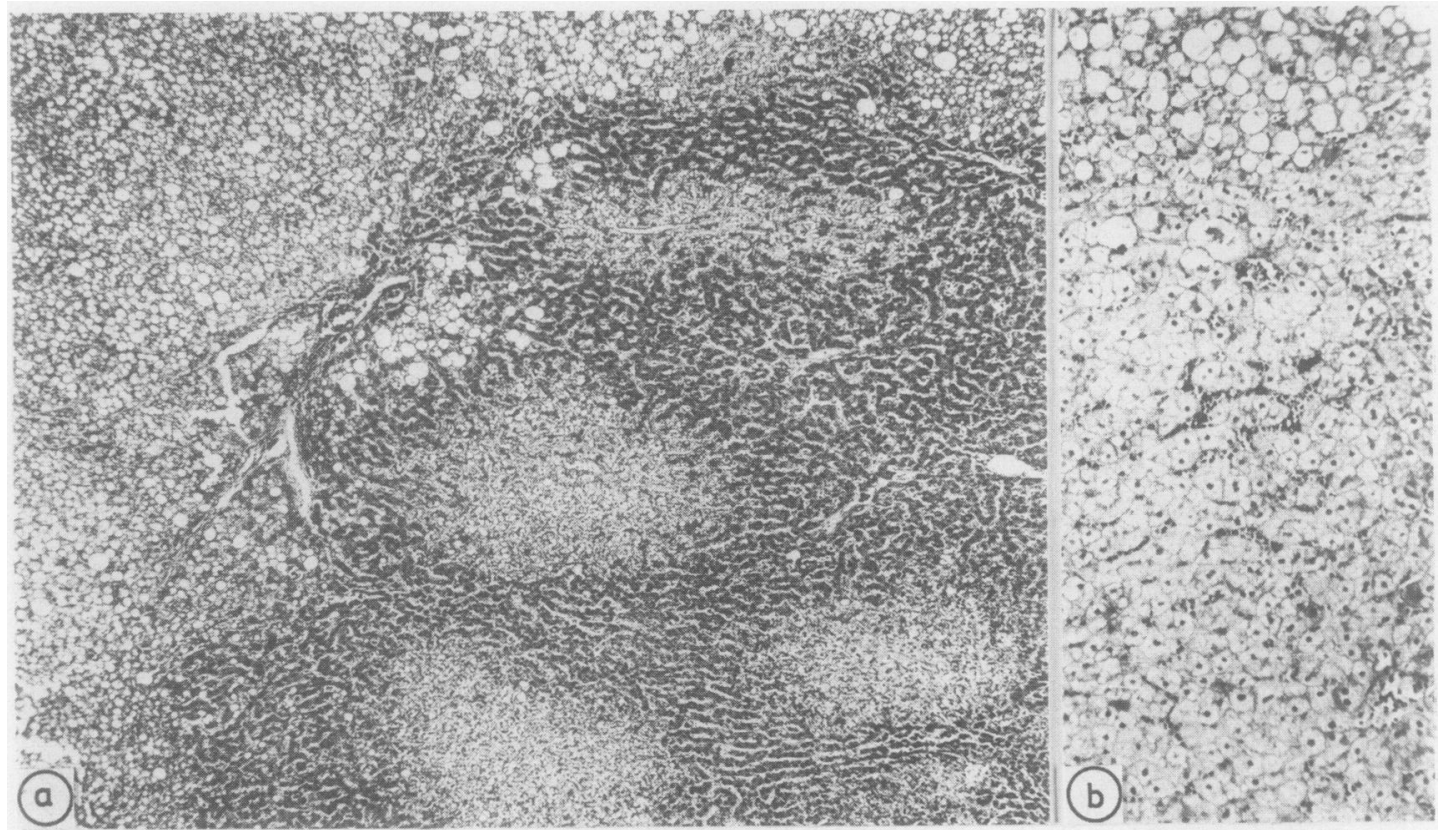

Fig. 3 Nodular hyperplasia of liver (a) with nodule composed of acidophilic cells resembling normal hepatocytes, among which several areas of clear cells are seen. Note fatty change in extranodular parenchyma. (b) Periportal nodules of clear cells visible in adjacent liver tissue. (van Gieson.) $\times 40(a) ; \times 90(b)$.

men with focal nodular hyperplasia was lower $(\mathrm{p}<$ 0.001 ) than that of any other group.

\section{Discussion}

A cancer metastasis is considered to be the most common type of liver tumour. ${ }^{2}$ Of all the patients with cancer $24 \%$ to $49.4 \%$ had metastases in the liver at the time of death. ${ }^{22}$ The incidence of benign hepatic tumours has usually been reported to be low, with the exception of cavernous hemangioma, which, after metastatic cancer, is the most common tumour of the liver. It occurred in $0.35 \%$ to $7 \%$ of patients in a large necropsy series. ${ }^{23} 24$ The incidence of benign bile duct tumours was low, varying from $0.6 \%$ to $2.8 \%$ in series of consecutive necropsies or liver needle biopsies. 1925 Focal nodular hyperplasia occurred in about $1-2 \%$ of necropsy specimens. ${ }^{26}$

In this study one case of malignant neoplasm was found that had already produced liver metastases; cavernous hemangioma was present in $20 \%$ of the specimens examined, benign bile duct tumours in $27 \%$, and focal nodular hyperplasia in $3 \%$.

The size of the tumours was considerably smaller than that usually reported. Benign bile duct tumours do not generally exceed $1 \mathrm{~cm}$ in diameter ${ }^{372527}$; in this study their mean size was only $1.3 \mathrm{~mm}$. The tumours of focal nodular hyperplasia $(0.8 \mathrm{~cm})$ and liver cell adenoma $(0.6 \mathrm{~cm})$ were small compared with the mean sizes of $5.6 \mathrm{~cm}$ and $7.5 \mathrm{~cm}$, respectively, in the report of Gold et al. ${ }^{7}$

The previously reported low incidences may, there-

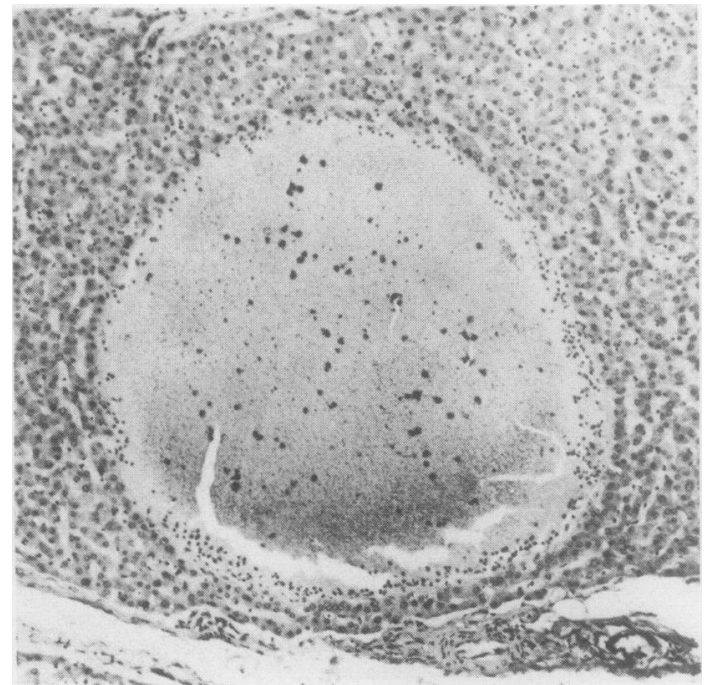

Fig. 4 Typical intralobular peliotic area with marginal leucocytosis and communications with sinusoids.

(Haematoxylin and eosin.) $\times 90$. 
Table 2 Age distribution of patients with benign hepatic tumours and related conditions in 95 men from necropsy series (figures in parentheses are numbers \%)

\begin{tabular}{|c|c|c|c|c|c|}
\hline \multirow{2}{*}{$\begin{array}{l}\text { Type of tumour or tumour like } \\
\text { condition }\end{array}$} & \multicolumn{5}{|c|}{ Age range (in years) } \\
\hline & $35-4 I(n=15)$ & $42-48(n=16)$ & $49-55(n=16)$ & $56-62(n=27)$ & $63-69(n=21)$ \\
\hline \multirow{3}{*}{$\begin{array}{l}\text { Focal nodular hyperplasia } \\
\text { Liver cell adenoma } \\
\text { Hemangioma } \\
\text { Bile duct tumour } \\
\text { Peliosis hepatis } \\
\text { Nodular regeneration hyperplasia } \\
\text { Cancer metastasis }\end{array}$} & $2(13)$ & $1(6)$ & $1(6)$ & & \\
\hline & $3(20)$ & $\begin{array}{l}2(13) \\
4(25) \\
1(6)\end{array}$ & $\begin{array}{l}3(19) \\
6(38)\end{array}$ & $\begin{aligned} 7(26) \\
10(37)\end{aligned}$ & $\begin{array}{l}4(19) \\
6(29)\end{array}$ \\
\hline & & & & $1(4)$ & $1(5)$ \\
\hline
\end{tabular}

fore, reflect the low probability of detecting a small lesion in a large organ. The slight differences in the incidence of bile duct hamartomas in blind needle biopsies $^{19}$ and in a large retrospective necropsy survey ${ }^{25}$ lend further support to this view. At necropsy the tumours are often likely to be overlooked because of their small size.

An increase in incidence of benign bile duct tumours paralleled a corresponding increase with age, which confirms earlier results. ${ }^{37}$ Benign bile duct tumours are mostly found in men and are associated with cystic disease of the liver. ${ }^{28} 29$ An association with hepatic ischemia,${ }^{30}$ alcohol, or drug induced liver damage has been suggested. ${ }^{27}$ In this series bile duct tumours were found in association with bridging and periportal fibrosis of the liver and with chronic inflammation of the pancreas. ${ }^{31}$

In women gonadal contraceptives may exert a trophic effect on focal nodular hyperplasia ${ }^{32}$ or cavernous hemangioma, ${ }^{3}$ whereas an aetiological correlation of liver cell adenoma with the use of contraceptives is strongly supported. ${ }^{32}$ In this study focal nodular hyperplasia had occurred more often in men who were younger than those without tumours or those with tumours of other kinds. The mean age of 40.3 years corresponds to the mean age of men affected in the study by Knowles and Wolff. ${ }^{4}$ The incidence of hemangioma was not dependent on age. None of the patients we studied had a history of sex hormone treatment.

Peliosis hepatis has often been associated with pulmonary tuberculosis, whereas about $70 \%$ of the cases now seem to be chemically induced. ${ }^{9}$ Our patient with peliosis was a destitute alcoholic, and tuberculosis is not uncommon in these circumstances. Data on previous use of drugs were, however, not available, nor was there any history of hospitalisation for tuberculosis.

Nodular regenerative hyperplasia (nodular transformation) occurred in this series in a man who was an alcoholic. He had also received oral testosterone for impotence and subsequently intramuscular injec- tions, amounting to a total dose of $21.5 \mathrm{~g}$ over 23 months before his death. This type of lesion has been reported to be a rare complication in patients receiving anabolic or androgenic steroids, or oral contraceptives, ${ }^{32}$ and in patients with rheumatoid arthritis, Felty's syndrome, CRST syndrome, and myeloproliferative disorders. ${ }^{17}$ It has been suggested that is is either a reactive $\mathrm{e}^{33}$ or a premalignant condition. ${ }^{17}$

In conclusion, the mostly small, even microscopic size, and the symptomless nature of benign hepatic tumours has clearly produced the common belief that they are rare. In this consecutive series focal nodular hyperplasia occurred most often in the younger age groups and benign bile duct tumours in the older age groups. Although cavernous hemangioma, focal nodular hyperplasia, and liver cell adenoma are usually found in women, many men in this necropsy series were affected.

I thank Drs J Ahlqvist, Judit Mäkinen for their help with classifying the tumours; Professor M Salaspuro and JA for comments. Ms Riitta Korhonen performed the statistical calculations and Ms HilkkaLiisa Vuorikivi cut up the histological specimens.

This study was supported by a grant from the Finnish Foundation of Alcohol Studies.

\section{References}

${ }^{1}$ Edmondson HA, Peters RL. Liver. In: Anderson WAD, Kissane JM, eds. Pathology Vol. 2. 7th ed. St Louis: CV Mosby, 1977:1321-438.

${ }^{2}$ Edmondson HA. Tumors of liver and intrahepatic bile ducts. Atlas of tumor pathology. Sect VII; fascicle 25. Washington: Armed Forces Institute of Pathology, 1958.

${ }^{3}$ Ishak KG, Rabin L. Benign tumors of the liver. Med Clin North Am 1975;59:995-1013.

4 Knowles DM, Wolf M. Focal nodular hyperplasia of the liver. Hum Pathol 1976;7:533-45.

${ }^{5}$ Henson SW, Gray HK, Dockerty MB. Benign tumors of the liver. I. Adenomas. Surg Gynecol Obstetr 1956;103:23-30.

${ }^{6}$ Adam YG, Huvos AG, Fortner JG. Giant hemangiomas of the liver. Ann Surg 1970;172:239-45. 
${ }^{7}$ Gold JH, Guzman IJ, Rosai J. Benign tumors of the liver. Pathologic examination of 45 cases. Am J Clin Pathol 1978;70:6-17.

${ }^{8}$ Thomas DB. Role of exogenous female hormones in altering the risk of benign and malignant neoplasms in humans. Cancer Res 1978;38:3991-4000.

${ }^{9}$ Spech HJ, Liehr H. Peliosis hepatis, eine klinische Bestandsaufnahme. Zeitschrift für Gastroenterologie 1982;20: 710-21.

${ }^{10}$ Kato M, Sugawara I, Okada A, et al. Hemangioma of the liver. Diagnosis with combined use of laparoscopy and hepatic arteriography. Am J Surg 1975;129:698-704.

${ }^{11}$ Madayag MA, Bosniak MA, Kinkhabwala M, Becker JA. Hemangiomas of the liver in patients with renal cell carcinoma. Radiology 1978;126:391-4.

12 Taylor CR, Taylor KJ. An incidental hemangioma of the liver: the dilemma of patient management. J Clin Gastroenterol 1981;3:93-7.

${ }^{13}$ Homer LW, White HJ, Read RC. Neoplastic transformation of $\mathbf{v}$ Meyenburg complexes of the liver. J Pathol Bacteriol 1968;96:499-502.

${ }^{14}$ Chang WWL, Agha FP, Morgan WS. Primary sarcoma of the liver in the adult. Cancer 1983;51:1510-7.

${ }^{15}$ Christopherson W, Mays T, Barrows G. A clinicopathologic study of steroid related liver tumors. Am J Surg Pathol 1977;1:31-71.

${ }^{16}$ Wetzel WJ, Alexander RW. Focal nodular hyperplasia of the liver with alcoholic hyalin bodies and cytologic atypia. Cancer 1979;44:1322-6.

${ }^{17}$ Stromeyer FW, Ishak KG. Nodular transformation (nodular "regenerative" hyperplasia) of the liver. A clinicopathologic study of 30 cases. Hum Pathol 1981;12:60-71.

${ }^{18}$ Leevy CM, Popper H, Sherlock S. Diseases of the liver and biliary tract. Standardization of nomenclature, diagnostic criteria and diagnostic methodology. Castle House Publications, 1979.

19 Thommesen N. Biliary hamartomas (von Meyenburg's complexes) in liver needle biopsies. Acta Pathol Microbiol Scand 1978;86:93-9.

${ }^{20}$ WHO. Histological typing of tumors of the liver, biliary tract and pancreas. In: Gibson JB, Sobin LH, eds. International histological classification of tumours. Geneva: WHO; No 20. 1978.

${ }^{21}$ Miyai K, Bonin ML. Nodular regenerative hyperplasia of the liver. Report of three cases and review of the literature. Am J Clin Pathol 1980;73:267-71.

${ }^{22}$ Abrams HL, Spiro R, Goldstein N. Metastases in carcinoma Analysis of 1000 autopsied cases. Cancer 1950;3:74-85.

${ }^{23}$ Ochsner JL, Halpert B. Cavernous hemangioma of the liver Surgery 1958;43:577-82.

${ }^{24}$ Feldman M. Hemangioma of the liver. Am J Clin Pathol 1958;29:160-2.

${ }^{25}$ Chung EB. Multiple bile duct harmartomas. Cancer 1970;26:287-96.

${ }^{26}$ Poulsen H, Christoffersen P. Atlas of liver biopsies. Copenhagen: Munksgaard, 1979:26.

${ }^{27}$ Henning H, Friedrich K, Luders CJ. Laparoskopischer Aspekt und klinische Relevanz von Cholangiofibromen. Zeitschrift für Gastroenterologie 1982;20:744-51.

${ }^{28}$ von Meyenburg H. Uber die Cystenleber. Beiträge Pathologie und Anatomie 1918;64:477-532.

${ }^{29}$ Melnick PJ. Polycystic liver. Archives of Pathology 1955;59: 162-72.

${ }^{30}$ Popovsky MA, Costa JC, Doppman JL. Meyenburg complexes of the liver and bile cysts as a consequence of hepatic ischemia. Hum Pathol 1979;10:425-32.

${ }^{31}$ Karhunen PJ, Penttilä A, Liesto K, Männikkö A, Möttönen $M$. Benign bile duct tumours, non-parasitic liver cysts and liver damage in males. $J$ Hepatol (in press).

${ }^{32}$ Ishak KG. The liver. In: Riddell RH, ed. Pathology of drug-induced and toxic diseases. New York: Churchill Livingstone; 1982: 457-513.

${ }^{33}$ Smith JC. Non cirrhotic nodulation of the liver. Arch Pathol Lab Med 1978;102:398-401.

Requests for reprints to: Dr Pekka J Karhunen, Department of Forensic Medicine, University of Helsinki, Kytösuontie 11, SF-00280 Helsinki, Finland 